\title{
Activists angry at fallout from AIDS drug trial allegations
}

A report due out this month aims to settle serious questions about a clinical trial of an AIDS drug in Uganda. But patient advocates say that the furor over the trial has already caused severe damage-by eclipsing the poor treatment of clinical researchers in developing countries ๖ and by undermining the fight against AIDS.

The trial, which is called HIVNET 012 and was funded by the US National Institutes of Health (NIH), tested whether short courses of the drug nevirapine could prevent pregnant women in Uganda from passing the disease to their babies. But in December last year, a series of articles by the Associated Press alleged that there were serious flaws with record-keeping in the trial after it started in 1997.

The NIH, backed by many scientists and AIDS activists, says the flaws were not serious enough to undermine the study's finding that the drug regimen works. To clarify the situation, the agency asked the US Institute of Medicine to conduct an independent study of the issue. Their report is expected to be published in late March.

But advocates say that the report is unlikely to resolve the most important lesson from the Ugandan trial: that poor countries cannot be expected to perform research to US standards without comparable funding.

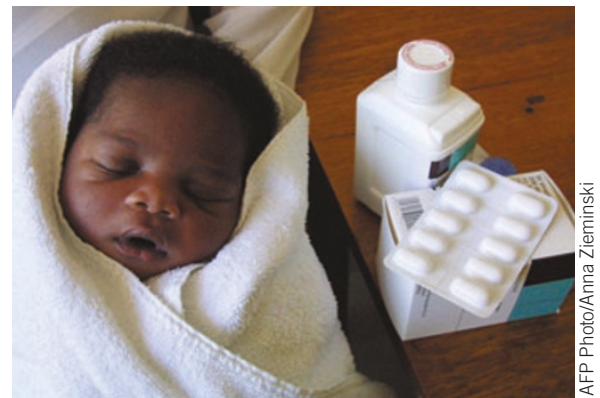

Child protection: Furor over nevirapine may have undermined HIV prevention efforts.

Arthur Ammann, a doctor and president of the nonprofit group Global Strategies for HIV Prevention in San Rafael, California, says the Ugandan investigators who conducted HIVNET 012 were told by the NIH that they could not receive money to offset overhead costs. This type of funding, which is routinely given to US institutions that receive $\mathrm{NIH}$ grants, goes towards such items as buildings, instruments, computers and record-keeping systems. "To ask people overseas to do trials to our standards without giving them comparable resources is a slap in the face," Ammann says.

As a result of lobbying by Ammann and other advocates, the NIH changed its policies after the HIVNET 012 trial ended. The agency now allows overseas grantees to receive overhead costs of up to eight percent on top of grants-still much less than the $30 \%$ or more awarded to US institutions. The NIH has also begun funding more training for clinical investigators in developing countries.

But critics say these are only the first steps, and that they would like to see complete parity with US clinical trial researchers. Without this, they say that problems are likely in other investigations, particularly in light of the growing amount of clinical research on HIV vaccines, malaria and tuberculosis in developing countries. "We've got to do everything we can to support research infrastructure there," Ammann says.

Meanwhile, other advocates are fighting to convince pregnant women in developing countries that it is still safe to take nevirapine-a drug they say has prevented thousands of women from passing HIV on to their babies.

They say the Associated Press articles have reignited confusion and fear among AIDS patients. "There are people going on the radio and telling people to stop taking nevirapine," says Nathan Geffen, national manager for the Treatment Action Campaign, an advocacy group based in South Africa. "This is having consequences for public health.”

Erika Check, Washington DC

\section{Strict NIH ethics rules provoke mixed response from scientists}

Sweeping new rules designed to curb conflicts of interest at the US National Institutes

of Health (NIH) have been met with both approval and anger.

The rules, introduced by director Elias Zerhouni on 1 February, limit employees' relationships with outside organizations. They were established in response to a series of reports in the Los Angeles Times beginning in late 2003 and a subsequent congressional hearing. These showed that numerous NIH scientists were paid consultants to drug companies that also had financial stakes in agency recommendations on research.

The new policy bars NIH employees from paid and unpaid consulting work with drug companies, universities, trade groups, health care providers or any other organization that interacts with the agency. In addition, top scientists cannot own stock in companies that do business with the NIH, and all other employees are limited to investments of $\$ 15,000$.

$\mathrm{NIH}$ staff complained that the policy unjustly punishes all 18,000 workers for the actions of a few. Zerhouni initially favored less stringent restrictions but changed his mind as new conflict of interest cases emerged and he came under increasing pressure from Congress.

Employees were particularly annoyed at having to sell stocks at a time when many pharmaceutical share prices are falling. Many staff criticized the new rules during an in-house meeting on 2 February. Several contacted the American Civil Liberties Union to inquire whether the rules are legal.

The Federation of American Societies for Experimental Biology (FASEB), a Washington, DC-based group representing over 65,000 biomedical scientists, expressed concern that the restrictions might prevent $\mathrm{NIH}$ scientists from joining or working with professional societies. The group is hosting a conference in June to discuss the relationship between researchers and industry.

Opponents of the rules say they could also hinder NIH efforts to work with industry in order to translate discoveries into marketable drugs or medical devices. But Mark Rohrbaugh, director of the NIH Office of Technology Transfer, says the regulations will not bar relationships between drug companies and scientists that take place on NIH time, rather than as outside activities.

Zerhouni indicated that the consulting ban is here to stay but promised that the agency will review and possibly revise parts of the rules after a one-year trial period. Interested parties can also submit comments during a 60-day period.

Despite the complaints, some outside the agency said the stringent measures are necessary to remove any appearance of conflicts of interest. Sheldon Krimsky, who has studied research ethics at Tufts University in Medford, Massachusetts, says the rules should be expanded to cover scientists serving on NIH advisory committees as well as those at other academic institutions. "There is a whole lot more that has to be done," he says.

The NIH made another long-awaited announcement in February about open access to research results. The agency urged $\mathrm{NIH}$-funded researchers to put copies of their papers in a planned online agency archive within 12 months of publication.

Tinker Ready, Boston 